\section{ORIGITAT COMMUUTICATIOTS.}

\section{THREE LECTURES ON THE CORRELATION OF PSYCHOLOGY AND PHYSIOLOGY.}

By DANIEL NOBLE, M.D., Visiting Physician to the Clifton Hall Retreat, near Manchester.

[Delivered at the Chatham Street School of Medicine, Manchester, June 1854.]

LECTURE I.

GESTRAL REXARKS OX TBE PHYSIOLOGY OF THE BRAIN AND NERVOUS SYBTEM. THE REFLEX FUNCTION. OFTICE OF THE GREAT BYMPATHETIC. BENBATION $\triangle$ NID THE BESPONDENT MOVEMENTS. PHYSICAI APPETITES.

Frow the remotest periods of physiological speculation, the brain and nervous system have been supposed to have some special connexion with the manifestations of conscious life. So early as the Greek civilisation, there were philosophers maintaining even the distinction between the nerves of movement and those of feeling. But although such doctrines vere obscurely taught by the ancients, it has only been in modern times that they have received systematic development and a scientific form. Unzer, who wrote in the latter half of the last century, refers to the transmission of external impressions as sensations to the mind, and to the spontaneous conceptions which result in roluntary motion, and asks: "How could it be possible to explain these two classes of phenomena, if the existence of difference in the fibrils of the same nerve be not admitted ?"* Sir Charles Bell, by his experiments, gave to this notion that precision and certainty which demonstration alone can furnish.

And so with regard to the encephalon. Long before the time of Gall, speculative physiologists suggested the probability of its distinct parts subserving particular mental operations. Only a few years prior to the publication of Gall's views, it was observed by Prochaska: "Since the brain, as well as the cerebellum, is composed of many parts, variously figured, it is probable that nature, which never works in vain, has destined those parts to various uses; so that the various faculties of the mind seem to require different portions of the cerebrum and the cerebellum for their production." It was Gall, however, who gave vividness to this idea, and a certain scientific shape. His physiology of the brain, in correlation with analytical psychology, has received a much larger share of attention and consideration than any which preceded it. Phrenology, however, as a system, has not receired that confirmation from later inrestigations, which, at one time, was anticipated by many physiologists.

Of late years, the labours of Dr. Marshall Hall, Dr. Carpenter, the late lamented Mr. Newport, Mr. Solly, and some others, in this Stilling, partienler, on the continent, have done much to advance the physiology of the brain and nerves; more especially in giving to it a greater exactness and a more demonstrable character. They have perfected it, indeed, to a degree which, a quarter of a century ago, would scarcely have been considered possible.

I will now proceed to furnish a summary of what may be doemed the existing state of our knowledge upon this subject, taking it for granted that my hearers have already a sufficiently accurate acquaintance with the descriptive anatomy of the structures in question.

You are awrare that, whilst the substance of the brain and nerves in appearance and general character has everywhere artain similarity, there is yet an obvious divisibility of it into two distinct kinds- the grey and the white matter; a divisibility which applies alike to the encephalon, the spinal cord, and the nerres. The difference in these nerrous subatances is not an affair of colour only; it applies also to their intimate structure and organisation: the white matter

- Dr. Leycock's Translation for the 8ydoahem Socioty.

- Dr. Iaycoek' Trandation. is made up of bundles of tubular fibres, whilst the grey is composed of aggregated cells, and is often denominated the vesicular neuring. To collections of this vesicular substanue, the term ganglion is very generally applied, because th: knots of nervous matter which formerly were supposed to give origin to the nerres, and which are distributed 80 largely throughout the body, are vesicular in their composition. And thus the identity in structural constitution has led to employment of the word ganglion as a common term But the ganglionic or spheroidal form is not at all essential as was at one time supposed, to the constitution of what is now called ganglionic substance.

Physiological and pathological researches have rendered it more than probable, that the vesicular and the fibrous substances have, unirersally, separate and distinct offices in the animal economy. Gall, noticing the extraordinary vascularity of the grey tissue, taught that it was the first formed, and that it constituted at once the producer and the matrix, as he called it, of the white substance; a fact which he enunciated as general, in regard both to the brain and nerves. This theory, however, retains no hold upon physiologists of the present day, who simply maintain that the ganglionic structures are the source of functional change, and that the fibrous matter is for the conduction of impressions originating in the former. In the promulgation of this theory, Mr. Solly shares probably in the most eminent degree. *

In studying the vital characteristics of man and animals, aided by the lights of anatomy and physiology, we judge of their sensibility and psychical endowment by watching the phenomens which exhibit themselves in movement and other expressions of activity and consciousness; and, in deducing conclusions concerning the springs and the quality of particular actions and conduct, we look very properly to the analogies gained in the introspection of ourselves. Thus premising, I will pursue the several processes which take place through the instrumentality of the brain and nervous system, discussing, in the present lecture, the simpler manifestations of nervous function, and, in the two succeeding ones, proceeding with the more elevated displays of psychical capability.

Although not actually demonstrated, it is yet rery rational hypothesis, based upon the clearest analogy, that, distributed largely and very minutely along the whole cutaneous and mucous surfaces, there is vesicular neurine, forming the peripheral expansion of nervous filaments, which may be likened to the structure of the retina as it expands itself behind the vitreous humour. When an irritant impression is made upon the surfaces thus supposed to be supplied, a respondent movement ensues, unless the controlling and restraining influence of the will, or some other qualifying circumstance, prevent it; and this movement does not necessarily involve any consciousness whatever. The impression wrought upon the superficial nerrous substance is conveyed by fibrous filaments to the resicular neurine within the spinal cord, in which a vital change occurs-an influence which expands itself in an outward direction, and, through other filaments, induces muscular contraction.

It is a receired doctrine that the grey matter, continuous throughout the whole length of the spinal cord, forms the analogue of the ventral ganglia, separate in the articulata. If one of these latter, the centipede for example, be divided into several parts, each segment will move upon the application of an outward stimulus. Amongst vertebrated creatures, in which a coalescence of ganglia in the spine has place, frogs exhibit such movements very strikingly. If the skin below the head be irritated, after detachment of the encephalon from the spinal cord, motion, the same in its outward cháracter as that which ordinarily follows upon sensation, will ensue. The unconscious nature of this phenomenon becomes still more obvious, when that portion of the cord which is immediately above the origin of the crural nerves is divided; irritate the hind legs under such 
circumstances, and they are seen to retract in the most lively manner. Corresponding phenomens may be observed iri the higher classes of animals, after decapitation. Eren in man, certain pathological states, which involve some breach of continuity between the brain and spinal cord, will show the same thing-involuntary movement respondent to an impression of which there is no sensational consciousness.

Movements taking place under the circumstances decribed, have been denominated reflex, excito-motory, and automatic. None of these expressions constitute very exact definitions ; provided, however, the function designated be rightly appreciated, the particular term employed is not of 10 much consequence.

The purpose of the spinal axis and its reflex function would appear to be the conservation of the organism, through excitation of the respiratory acts, by its governance of the various orifices of ingress and egress, and by its contribution to the integrity of some other processes in which reflex movements participate.

I must here make a few remarks upon the ganglia of the so-called sympathetic system of nerves. These ganglia are scattered largely throughout the body; in front of the vertebral column they form two distinct and regular chains, the whole being connected by nerrous filaments extended in all directions, and especially accompanying the bloodvessels. The precise function of this portion of the nerrous system is somewhat obscure. Consciousness can hardly be supposed to have place in its exercise. It most likely communicates a susceptibility to certain motions involved in the processes of circulation, nutrition, and secretion; an influence not needed for their simple accomplishment, but required in the animal economy, in order that they may become related with, and in a measure subordinated to, the higher operations of the brain and nervous system.

That the functions purely organic are, in some way or another, under the influence of the nervous system, in man and the higher classes of animals, is undoubted; and that this influence operates immediately through the sympathetic system, is inferred from the following amongst other circumstances.

The anatomical distribution of this system affords to such an estimate of its functions, antecedent probability; but numerous facts exist, which give to this view a much higher character than that of mere hypothesis. Dr. Axmann, of Berlin, some years ago, instituted experiments upon frogs, with the intention of elucidating this department of physiology. Upon dividing the crural nerves, at their origin between the spinal cord and spinal ganglion, he found that paralysis of motion and sensation ensued, without sensiblc prejudice to the purely organic processes. On the division, however, being made between the ganglion and the communicating branch of the sympathetic, there resulted, in addition, pallor of the skin, partial desquamation of the epidermis, softening and friability of the tissues, minute extravasations of blood, and odema. Upon these experiments, Romberg has the subjoined remarks. "If the sciatic nerve is divided below the part at which the fibres of the communicating branch, or, in other words, sympathetic elements, are introduced into it, we find disturbances in the circulation, which are distinctly manifested in the web of the foot. The circulation is rendered indolent and irregular; the dilated ressels are overcharged with blood-corpuscles, and in a few ressels the blood is arrested."

It is known that certain drugs act upon particular divisions of the nerrous system, by a sort of elective affinity. And it is observed that some poisonous substances exert their primary influence upon the respiratory movements, which are mainly under the control of the excito-motory arstem; and again, that others, in the first instance, arrest the heart's action, presumably from injury done to the oympathetic. "Poisoning with tobacco and arsenic," says Iomberg, "paralyses the cardiac nerres and arrests the cir-

- Nervous Diseases of Man. Dr. Siereking s Tranalation for the Byden. ham 8oeioty. culation, while the respiratory movements continue . ..... On the other hand, the West Indian arrow poison paralyse: the respiratory and voluntary movements, at the same time that the action of the heart continues, and may be kept up by artificial respiration."*

Disorder of the organic functions sometimes takes place in but one of the symmetrical halves of the body, as if from some corresponding perversion of nervous agency. Sir Henry Holland has related cases in which copious perspiration was limited in this way.t

Altogether, the evidence favouring the theory which assigns to the sympathetic nervous system a controlling influence over the processes of circulation, nutrition, and secretion, is, from its cumulative character, exceedingly strong, although it may not amount to actual demonstration.

The primary and more simple forms of consciousness arise through the instrumentality of the nerves and ganglia of the senses, which constitute the media through which impressions are obtained of the qualities of external objects. Although, under some circumstances, the senses may be excited from internal conditions, sensation ordinarily and naturally developes, in the percipient, a consciousness of outiness in the excitant. The five external senses, as in consequence they are called, reveal the physical qualities of objects, their odour, savour, sound, colour, and density. And the functions of smell, taste, hearing, sight, and touch, are exercised, respectively, through organisation very similar to that of the functions already described. Vesicular neurine--presumptively, when not demonstrableexists at the peripheral extremity, in a state of expansion; and again at the central termination of the nervous fibres, as ganglion.

Vesicular neurine distributed upon the lining membrane of the nostrils possesses a specific sensibility to odorous matters; the impression which these make is conveyed by conducting fibrous filaments to the bulbi olfactorii, the ganglionic centres wherein the sense of smell is exercised.

The vesicular expansion of nervous filaments upon the lingual surface and the palate are specifically impressed by sapid particles; and the impression, being passed along fibrous filaments to the proper ganglionic centres, induces the consciousness of taste. There is some uncertainty concerning the nervous apparatus of this sense, in great measure owing to the mixture of filaments from different nervous trunks on the gustatory surfaces. The special character of taste as a sense, however, and the distinctness of its nerrous filaments and central ganglia, can hardly be doubted. Twenty years ago, paralytic cases came beneath my own notice, and were published at the time in the Iondon Medical Gazette, showing the abolition of tactile with persistence of gustatory sensibility, and vice versá.

Vesicular neurine, spread largely within the internal ear, receives the vibratory undulations constituting the external cause of sound; the fibrous filaments of the auditory nerve conduct the influence to certain grey nuclei in the posterior pyramids of the medulla oblongata, that form the ganglia of hearing.

The retina is largely composed of vesicular neurine; visual impressions are carried along the course of the optic nerves, and attain the corpora quadrigemina, which there is every reason for concluding to be the ganglia of sight.

The four modes of consciousness just recounted, being accomplished by distinct nerves, and by organic apparatuses limited to particular regions of the body, have been denominated the special senses.

But there is developed a sense-consciousness not limited to any particular organ, but which refers itself more or less to the whole frame-common sensation. This sense resides principally in the skin; it is particularly acute at the mucous orifices; it exists, however, in the interior structures, but in a condition less intense. It is best illustrated by the simple notion of resistance. Its modifications com. 
prise the several impressions essential to ideas of the hard, the soft, the rough, the smooth, the hot, the cold, the moist, the dry, and so on. It is, moreorer, through this censibility that we appreciate the state of the musclesobtain the muscular sense.

This fifth sense also is, presumably, awakened through the vesicular extremities-the peripheral expension of fibrous filaments. Whether the grey substance and white fibres originating and conducting common sensation be the same as those which subserve the spinal reflex function, is - question yet undecided. This much, however, may be admitted: the communicated impression ascends along the posterior columns of the spinal cord, and attains grey vesicular centres-the ganglia of common sensation.

Physiologists are not agreed as to the identity of these structures; they must be expected, however, like the other sensory ganglia, to be somewhere at the base of the cranium; and I am myself disposed to think that the vesicular nuclei within the lateral lobes of the cerebellum constitute the encephalic centres of common sensation. Many years ago, Foville assigned this function to the aggregate cerebellum; and others, with great plausibility, have adrocated the same notion. The anatomical connexion which exists between the ganglionic structures in question and the posterior columns of the spinal cord, through the corpora restiformia, favours the idea which I have advanced; and there are various physiological and pathological facts which go to corroborate it.

The experiments of Magendie and Longet show that the slightest touch of the fibres of the restiform bodies induces violent pain.* Hutin relates a case in which the sense of touch was so exalted that, upon the least contact, intolerable pain and restlessness ensued, with corresponding muscular contractions, resembling those produced by an electric discharge. The patient ultimately died in the most terrific convulsions, prostrate and exhausted. On examination after death, there was found, amongst other changes, atrophy of the cerebellum. "Its medullary centre, as compared with that of another subject, was a third less in size in either hemisphere. The white substance, which, in the normal condition, occupies the centre of the corpus rhomboidale, had ceased to exist; so that the fimbriated margins of this portion approached the centre, and only formed a small pyriform, very hard, greyish brown body."

The riew just advanced would seein to reconcile, in some degree, the doctrine of Gall with that of Flourens. The former, as all are aware, taught that the entire cerebellum forms the organ of the sexual instinct; and the latter (supported in his conclusion by most modern physiologists) conceives his experiments to have established that its office is to co-ordinate muscles acting in combination at the mandate of volition. It has also been thought to exercise some special influence in ballancing the body. Now, if some portion of the cerebellum subserve ordinary feeling-common sensation, its connexion with the function imputed io it by Gall is sufficiently intelligible, without adoption of the phrenological doctrine. Numerous facts certainly appear to indicate some relation between the cerebellum and the organs of generation; but such facts receive an interpretation just as rational by reference to the tactile sensibility of these latter, as by unqualified admission of the phrenological idea. In the view regarding the muscular office of the cerebellum, the facts bearing upon it may receive an explanation by considering the probable influence of its peripheral vesicular neurine-its cortical grey matter-in determining to the muscles some reaction respondent to their feeling. The experiments of Budge and Valentin demonstrate an apparent influence of the cerebellum, when irritated in its cortical portion, upon the testes and rasa deferentia, in occasioning their retraction. $\neq$

If, indeed, the idea be ultimately confirmed, which assigns to the structure in question the co-ordination of muscles in voluntary movement, it perfectly comports with my own hypothesis concerning the ganglia of common sensation; for, as Dr. Carpenter remarks, "all voluntary movements require the guridance of eneations; and most of these are of the tactile find."*

Let the whole case, horrever, be as it may, common sensation must have its proper ganglia somewhere; and it cannot be doubted that these, through the spinal cord, are in some sort of connexion with every sentient structure.

I would beg my hearers to understand that, with respec" to any hypothesis advanced in these lectures, the individus facts cited in its support are not offered as proof, but simpl as exemplifying the kind of evidence which, by accumuls tion, might adequately substantiate the same.

All the sensory ganglia, it may here be noticed, besides their instrumentality in inducing the simpler modes of consciousness, produce reactions very often in the muscular system, when, through afferent nerres, they are stimulated from without; and that, too, in frequent independence of thought or volition. It would seem that impressions received in some particular ganglionic structure may be diffused through a whole chain of connected ganglia, and so bring about respondent movements of very raried character. These Dr. Carpenter designates consensual, not in the meaning of consentaneousness, but as occurring with, in dependence upon, ense. A young infant, long before distinct thought can have been awakened, exhibits restlessness from contiguity to its mother's bosom, provoked, it is probable, by the odour of the mammary fluid. An odious taste simply may determine the involuntary act of vomiting; a loud and unexpected sound will occasion slight but very general contraction of the muscles, as in startling; the eye, when dazzled, is rapidly withdrawn from the light; and a sudden dash of cold water provokes deep inspiration and audible zobbing. These muscular actions are reflex, as to their modes of occurrence; but they differ from the reflex actions purely spinal in being essentiahy attended with consciousness; and they differ from ordinary movements in the circumstance that neither volition, nor ideas, nor mental emotion, properly speaking, are concerned in their production.

There are other sensibilities which are external in their related objects, but which do not form the medium of information concerning the world without, and so, on this account, do not come within any of the foregoing categories. These comprise the physical appetites of hunger and thirst. Nothing is made out with respect to the ganglionic centres of these affections. Probably they somewhere exist. among the tracts of grey matter at the base of the encephalon, there being much vesicular neurine there, the function of which is quite uncertain. But, upon this subjeet, conjecture on the basis of analogy alone exists at present.

\section{ON THE PATHOLOGY AND TREATMENT OF LARYNGO-TRACHEAL INFLAMMATION.}

\section{BY ROBERT TURNER, M.D.}

Orgersatros and reflection have impressed me with the belief that a common pathogenic condition pervades all inflammatory affections of the laryngo-tracheal mucous membrane; and that to this condition their leading characteristic, stridulous respiration, as well as their tendency to a fatal termination, is chiefly due : in other words, that the essential element of this class of diseasesof laryngitis, acute and chronic, and of croup, in all its rarieties-is the same. My object in the present communication is to develope these viers, and to point out what I conceire to be their application to practice.

The following positions embody a statement of some points in the physidlogy of the larynx; which, although well ascertained facts in vital dynamics, have not, I beliere, obtained a due practical recognition in pathology and therapeutics.
- Romberg. Op. eitat.
+ Op. oitet.
Op. citat. 